\title{
Focus on the learning styles of freshman design students
}

\author{
Halime Demirkan and Ö. Osman Demirbaş, Department of Interior \\ Architecture and Environmental Design, Faculty of Art, Design and \\ Architecture, Bilkent University, 06800 Bilkent, Ankara, Turkey
}

Using Kolb's Experiential Learning Model, this study explores learning styles of freshman design students in three consecutive academic years. Principal Component Analysis method is used to reduce the number of variables and classify them according to the priorities assigned to learning process by the design students. Findings showed that the distribution of design students through learning style preference was concentrated in assimilating group with coordinates close to the intersection of the axes of the Learning Style Type Grid. The bipolar perceive dimension indicated that the freshman design students are more related to the analytical skills of theory building, quantitative analysis and technology. Also, the bipolar process dimension showed that they have better behavioural skills compared to perceptual learning skills.

(C) 2008 Elsevier Ltd. All rights reserved.

Keywords: design education, experiential learning, learning styles

Corresponding author: Halime Demirkan demirkan@bilkent. edu.tr
$\mathrm{D}$ ifferent aspects of design epistemology are emphasised over the last 40 years. In the early years, the problems that designers deal with were described as 'ill defined' (Reitman, 1965) or 'wicked' (Rittel, 1972). Although the final goal is 'ill defined' at the beginning, the sub goals have to be well defined throughout design process by the designer (Akin, 1986; Lawson, 1990; Cross, 2006). Cross (1982) stated that while designers deal with the 'ill defined' problems, their 'mode of thinking is constructive' and they use 'codes that translate abstract requirements into concrete objects' (p. 226). Also, Cross (2001) explained 'designerly ways of knowing' and differentiated design from other ways of knowing and underpinned the importance of knowing, thinking and acting. Later, Cross (2006) added that designers should develop an intellectual awareness by making explicit analysis and comparison of the paradigms by underlying the approaches of Simon's 'rational problem solving' (Simon, 1996) and Schon's constructivism of 'reflective practise' (Schon, 1983, 1984, 1987).

Dewey (1933) had argued that reflective judgements are initiated when an individual recognises that there are 'problematic situations' that cannot be solved by formal logic. Schon accepted Dewey's concept of thinking in www.elsevier.com/locate/destud 0142-694X \$ - see front matter Design Studies 29 (2008) 254-266 doi:10.1016/j.destud.2008.01.002

(C) 2008 Elsevier Ltd. All rights reserved. Printed in Great Britain 
'problematic situations' as a starting point and aspired to explain 'the process of practical inquiry by combining conceptual analyses with empirical studies of expert practitioners' (Waks, 2001, p. 38).

Furthermore, Waks $(1999,2001)$ argued that reflective practise theories of both Dewey and Schon are alternatives to the model of technical rationality. Also, he added that they 'both address the same questions, and both reject the same wrong answers' (Waks, 2001, p. 40). The fundamental difference is the description of reflective practise where Dewey explained it within the framework of scientific thinking and Schon as a professional activity. Thus, Schon set out an epistemological alternative model to design education in which design professionals acquired knowledge from tradition and experience, rather than from science. Schon (1983) defined the role of the learner as an active 'practitioner that becomes a researcher... and engages in a continuing process of self-education' (p. 299). Also, he described the instructor as a facilitator that provides information and resources to the designer's inquiry and professional growth. The instructor is not an expert who is responsible for conveying standardised and scientifically determined knowledge to guide the design actions but a communication specialist who does the reflective conversation.

Kolb (1984) has built Experiential Learning Theory (ELT) on a set of theories as Dewey's pragmatism, Lewin's social psychology, Piaget's cognitive-development, Ruger's client-centred therapy, Maslow's humanism and Perls' Gestalt therapy. Kayes (2002) advocates that Kolb's learning theory provides one of the few comprehensive and fully generalised models among the other experiential models that employ dialectic inquiry. Although Coffield et al. (2004) compare 13 models of learning styles according to four criteria as internal consistency, test-retest reliability, construct and predictive reliability and found to be meeting only one criterion that is the test-retest reliability. Despite Kolb and Kolb (2005a) explain the popularity of the ELT by its two characteristics as having a holistic approach and being interdisciplinary. Since ELT is widely accepted and generalised model and Learning Style Inventory test provides a framework for learning in design, it is a useful tool for exploring design education.

\section{Experiential Learning Theory}

ELT suggests that learning is a cycle that begins with experience, continues with reflection and later leads to action that becomes a concrete experience for reflection (Kolb, 1984). In the Experiential Learning Model, there are four phases of the learning cycle, namely concrete experience (CE), reflective observation (RO), abstract conceptualisation (AC) and active experimentation (AE) (see Figure 1).

In this cyclical process, learning begins with what Dewey (1938) described as a 'problematic situation': a design problem given to the design student in the studio. The problem can be explained as a discrepancy between the real 
Figure 1 Four learning phases

of Experiential Learning

Theory (revised from Kolb,

$1999, p .4)$

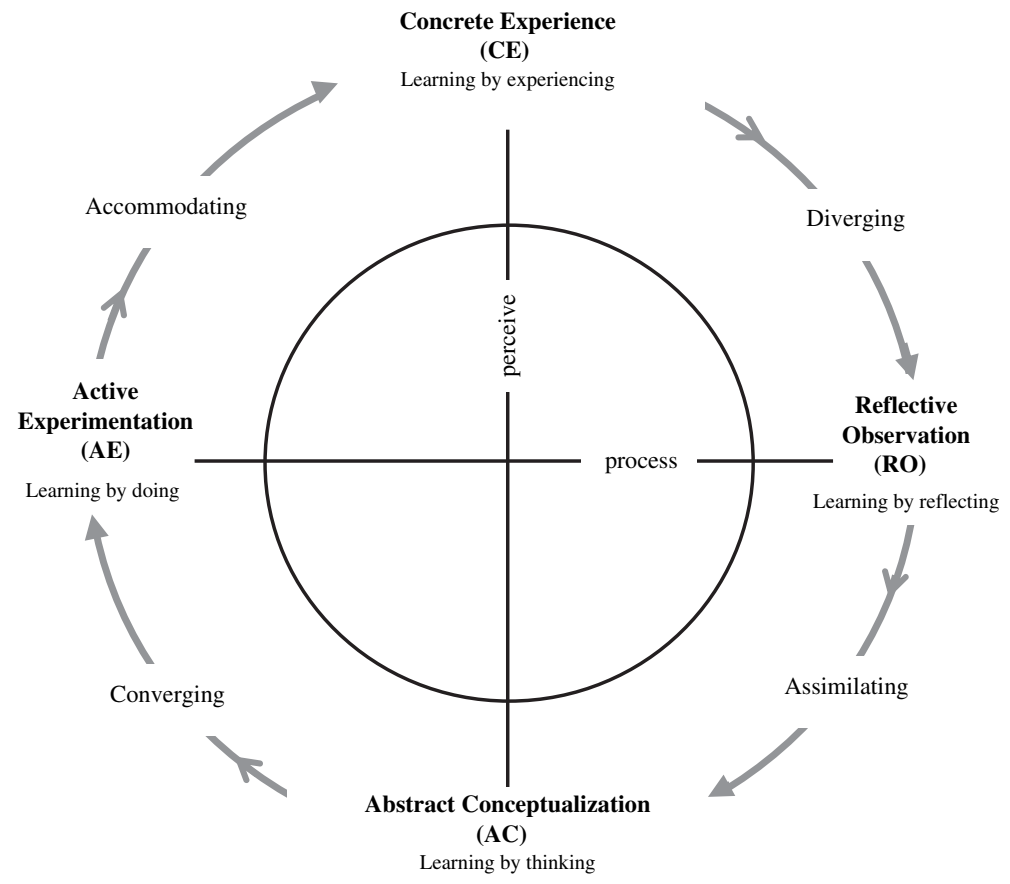

and ideal, between intention and action that stimulates the learner to acquire new information as part of an active search for alternative design solutions.

ELT portrays two bipolar learning dimensions, namely perceiving (the vertical axis in Figure 1) and processing (the horizontal axis in Figure 1). A combination of scores on the two dimensions classifies learners into one of four learning styles: accommodating (CE and $\mathrm{AE}$ ), diverging (CE and $\mathrm{RO}$ ), converging (AC and $\mathrm{AE}$ ) and assimilating (AC and $\mathrm{RO}$ ). From a hypothetical point of view, a learner would consciously move through all the phases of the learning cycle (Demirbas and Demirkan, 2003). However, most of the studies showed that all learners do not equally experience each phase of the cycle. Besides, none of the phases of the cycle is more important than the others. This suggests that the preference of learners among the phases of the cycle does not make them any better or worse learners (Kolb, 1984; Smith and Kolb, 1996; Willcoxson and Prosser, 1996).

During a design project, the student transforms a field of inquiry (problem) into a proposition or scheme (alternative solution). The learning process is characterised by continual dialogue. Students learn from sharing information with one another and instructors, and from the critiques of the jury members. The most important learning experience comes from what is known in other disciplines as self-reflection, a skill central to the acquisition of all design knowledge and skills, and one that is consciously developed (Newland et al., 1987; Demirbas and Demirkan, 2003). 
Many studies of learning styles have been conducted in the field of higher education (Guild, 1994; Hartman, 1995; Vermetten et al., 1999; Busato et al., 1998; Biggs, 2001; Coffield et al., 2004). Although the studies classify different learning types and/or styles in different ways, their aims and instructional approaches around the cycle of learning models are similar (Demirbas and Demirkan, 2007). Consequently, the learning process in design education can be underpinned by ELT of Kolb (1984). Recently, design educators have started to explore the characteristics of learning styles of students that can be used for the enhancement of learning in design (Demirbas, 2001; Demirbas and Demirkan, 2003, 2007; Kvan and Yunyan, 2005). This literature suggests that design students should learn by experiencing, reflecting, thinking and doing in the process of finding solutions to assigned design problems. Therefore, design education can be considered as being in line with the ELT of Kolb (1984).

The research problem is specified in three research questions:

1. What are the mean values for the four phases (CE, RO, AC and AE) and two combined scores (AE- RO and $\mathrm{AC}-\mathrm{CE}$ ) of the freshman design students? What is the location of the freshman design students on the Learning Style Type Grid?

2. Which phase (CE, RO, AC, and AE) of the learning cycle of the freshman design students is the most dominant one during design process?

3. What bipolar learning dimensions characterise the learning behaviours of the freshman design students?

\section{Method}

\subsection{Participants}

This study was conducted with a sample of 286 freshman students in three consecutive years in the Department of Interior Architecture and Environmental Design at Bilkent University. There were 111 freshman students in the first year, 88 freshman students in the second year and 87 freshman students in the third year. The age range was $17-27$ in all years. There was no significant relationship between the sample year and the learning style of the design students $\left(\chi^{2}=11.224, \mathrm{df}=6, p=0.082\right)$. Among the participants, there were 135 $(47.2 \%)$ males and $151(52.8 \%)$ females.

\subsection{Instrument and procedure}

The learning styles of the freshman design students were determined by using the Turkish version of the Learning Style Inventory (LSI) test of Kolb (1999) that contains 12 items. The preliminary Turkish version of the LSI test was developed and tested by Askar and Akkoyunlu (1993). They gave the translated test to 103 students with different disciplinary backgrounds: namely, as science $(37 \%)$, social sciences $(52 \%)$ and engineering $(12 \%)$. They reported that the alpha values ranged from 0.58 to 0.77 for the four basic (CE, RO, AC and $\mathrm{AE})$ and two combination items ( $\mathrm{AC}-\mathrm{CE}$ and $\mathrm{AE}-\mathrm{RO})$ where in the Kolb's 
(1984) study the range was from 0.73 to 0.88 . There may be several reasons for these lower scores; first there is a cultural difference between the two subject groups, secondly, the test was translated into Turkish and this may cause some difficulties in understanding of the respondent's and lastly, the number of subjects was smaller when compared to Kolb's study $(N=268)$. In this study, two bilingual experts who are native speakers translated it back to English in order to check the items with their originals. Few items are revised in Turkish translation according to their suggestions.

Data are described as ipsative if a given set of responses always sum to the same total as in LSI. Cattell (1944) coined the term ipsative for interpreting intraindividual measures meaningful in contrast to normative measures that are interpreted interindividually (Pedhazur and Schmelkin, 1991). In LSI, a subject is required to rank each of the four sentences either as 1,2, 3 or 4 for each of the 12 items; thus the total score for each sentence for each subject is always 10 (i.e., $1+2+3+4=10$ ). In the test, for example one of the questions is ' $I$ learn by feeling/watching/thinking/doing', and the respondent is asked to rank the four learning styles from 4 to 1, to the extent each learning style applies to him or her. The scoring ranks on one dimension are dependent on how a subject is measured relative to his or her other scores on that response set. Some researchers argued that ipsativity is inherent in data obtained from a forced ranking inventory in LSI (Chan, 2003) and leading to an artificial negative correlation between the four learning dimensions (Hermanussen et al., 2000). In order to overcome this limitation and reduce the number of variables by factor extraction, Principal Component Analysis method is applied to the data.

As a data reduction method, Principal Component Analysis is used that starts with the correlation matrix, where the variances of all variables are equal to 1.0. Extraction of the principal component results in a variance maximising (vari$\max$ ) rotation of the original variable space because the criterion for the rotation is to maximise the variance of the new variable called the factor. The variances extracted by the factors are called the eigenvalues. Kaiser (1960) is the most widely used one that proposed to retain only factors with eigenvalues greater than 1. Items that had relationships $50 \%$ and above with the factor component were thought to describe the factor and its related scale the best, thus those items would provide the best assessment for that particular scale. The final study included only these items with 0.50 or more loading weights.

\section{Results}

\subsection{Related to the distribution of learning styles}

First, the descriptive statistics for the study variables were computed (see Table 1), along with the internal reliability estimates (alpha coefficients). The mean value for $\mathrm{AC}-\mathrm{CE}$ is 7.44 and for $\mathrm{AE}-\mathrm{RO}$ is 5.20. The range of the alpha values was from 0.54 to 0.69 . 


\begin{tabular}{llllll}
\hline & Mean & $\begin{array}{l}\text { Standard } \\
\text { deviation }\end{array}$ & Minimum & Maximum & $\begin{array}{c}\text { Cronbach's } \\
\text { alpha }\end{array}$ \\
\hline CE & 24.27 & 5.58 & 14 & 42 & 0.68 \\
AC & 31.71 & 5.51 & 17 & 47 & 0.67 \\
RO & 29.39 & 5.14 & 15 & 41 & 0.58 \\
AE & 34.59 & 5.23 & 19 & 28 & 0.60 \\
AC-CE & 7.44 & 9.21 & -24 & 27 & 0.69 \\
AE-RO & 5.20 & 8.26 & -16 & & 0.54 \\
\hline
\end{tabular}

Based on these values, the location of the freshman design students can be described as assimilating learners (see Figure 2) by the coordinate points $(5.20$, 7.44) on the Learning Style Type Grid (Kolb, 1999). The cut point for the $\mathrm{AE}-\mathrm{RO}$ scale is +6 and the cut point for the $\mathrm{AC}-\mathrm{CE}$ scale is +7 (Kolb and Kolb, 2005b). The assimilating learners are defined by $\mathrm{AE}-\mathrm{RO}<6$ and $\mathrm{AC}-\mathrm{CE}>7$.

\subsection{Results related to the items}

Principal Component Analysis on the 48 items (12 statements $\times 4$ sentence endings, $N=286$ ) showed that 17 factors had eigenvalues greater than 1.00 . This analysis followed by varimax rotation resulted in four factors with eigenvalues greater than 1 (Table 2). Using factor loadings greater than \pm 0.50 , there were three factors after rotation with varimax with Kaiser normalisation. Since ipsative scores are interdependent, this may limit the factorability of the primary variables. The following findings are

Factor 1 (eigenvalue $=6.69,13.94 \%$ of total variance) loaded on five negative CE items and two AE items;

Factor 2 (eigenvalue $=4.37,9.09 \%$ of total variance) loaded on two negative $\mathrm{RO}$ items, one $\mathrm{CE}$ and one $\mathrm{AC}$ item;

Factor 3 (eigenvalue $=3.14,6.54 \%$ of total variance) loaded on two negative $\mathrm{AE}$ items and one $\mathrm{AC}$ item.

\subsection{Related to the bipolar learning dimensions}

The four primary variables are ipsative because of the forced-choice format of the instrument. 'The combination scores $\mathrm{AC}-\mathrm{CE}$ and $\mathrm{AE}-\mathrm{RO}$, however, are not ipsative' (Kolb and Kolb, 2005b, p. 12). Principal Component Analysis on the 24 items (12 statements $\times 2$ sentence endings equals $24, N=286$ ) showed that eight factors had eigenvalues greater than 1.00 . The varimax rotation resulted in four factors with eigenvalues greater than 1 (Table 3). Using the factor loadings greater than \pm 0.50 , there were four factors after rotation with varimax with Kaiser normalisation. The first factor can be interpreted as 'the thinking (AC) oriented perceiving dimension', and the rest as 'the doing (AE) oriented process dimensions' (see Figure 1). 


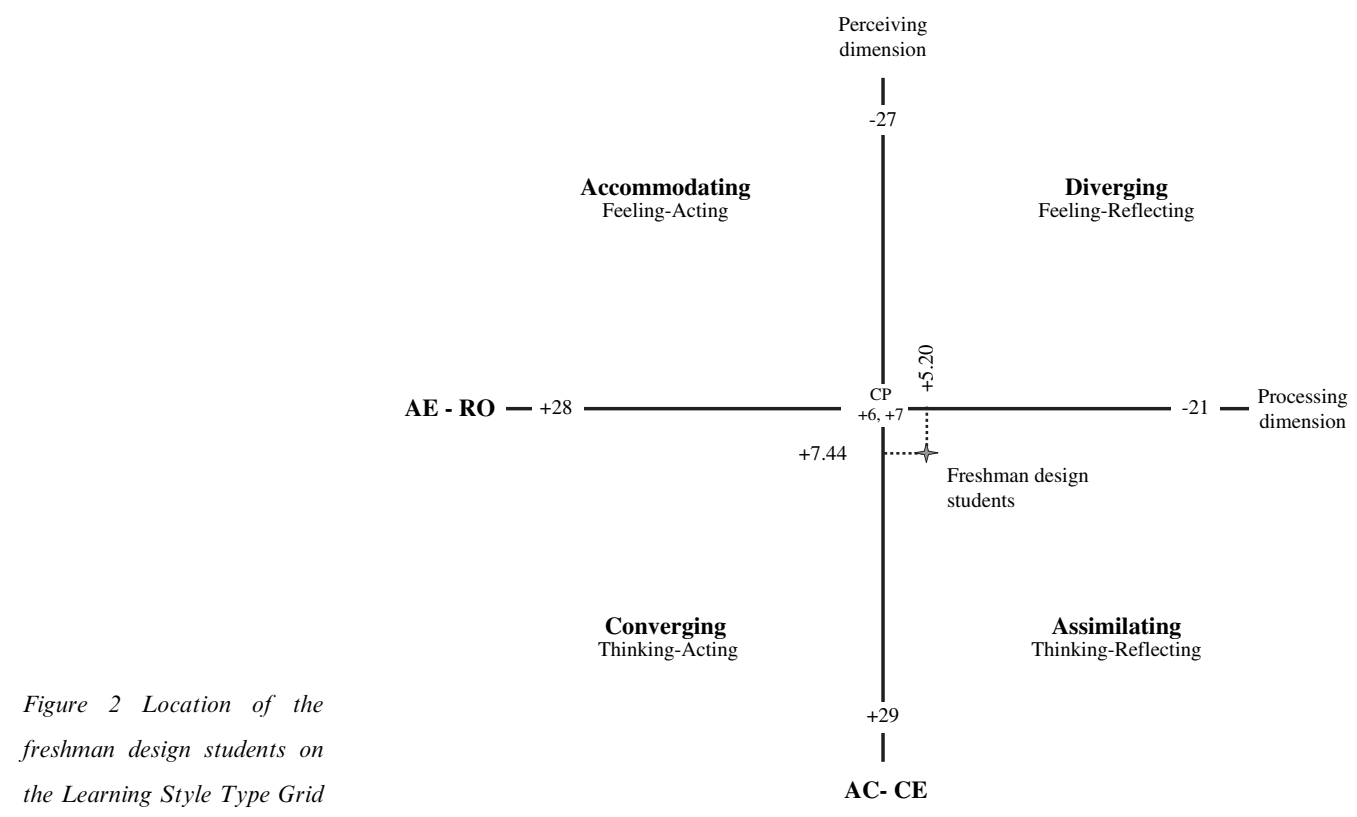

The bipolar data were analysed using the Principal Component Analysis of the $24 \times 24$-correlation matrix and the varimax rotation of 23 factors (i.e., $24-1$ factors). The following findings are

Factor 1 (eigenvalue $=4.51,18.79 \%$ of total variance) loaded on five $\mathrm{AC}-\mathrm{CE}$ items;

Factor 2 (eigenvalue $=2.25,9.36 \%$ of total variance) loaded on three AE-RO items;

Table 2 Results of 48 items

\begin{tabular}{ll}
\hline Items (loadings) & Sample items \\
\hline Factor 1 & \\
CE9 $(-0.857)$ & I learn best when I do not rely on my feelings. \\
CE4 $(-0.784)$ & I do not learn by feeling. \\
CE6 $(-0.772)$ & When I am learning I am not an intuitive person. \\
CE2 $(-0.696)$ & I learn best when I do not trust my hunches and feelings. \\
CE1 $(-0.656)$ & When I learn I do not like to deal with my feelings. \\
AE9 $(0.614)$ & I learn best when I can try things out for myself. \\
AE8 $(0.516)$ & When I learn I like to see results from my work. \\
Factor 2 & \\
RO3 $(-0.857)$ & When I am learning I am not quiet and reserved. \\
RO10 $(-0.824)$ & When I am learning I am not a reserved person. \\
CE3 $(0.587)$ & When I am learning I have strong feelings and reactions. \\
AC10 $(0.541)$ & When I am learning I am a rational person. \\
Factor 3 & \\
AE1 $(-0.858)$ & When I learn, I do not like to be active. \\
AE6 $(-0.656)$ & When I am learning, I am not an active person. \\
AC11 $(0.625)$ & When I learn, I evaluate things. \\
\hline
\end{tabular}


Items (loadings)

Factor 1

Perceiving activities

AC-CE6 (0.770)

$\mathrm{AC}-\mathrm{CE} 4(0.747)$

AC-CE9 (0.724)

$\mathrm{AC}-\mathrm{CE} 1(0.614)$

$\mathrm{AC}-\mathrm{CE} 2(0.586)$

Factor 2

Processing activities

AE-RO10 (0.814)

AE-RO3 (0.678)

AE-RO8 (0.504)

Factor 3

Processing activities

AE-RO9 (0.761)

AE-RO7 (0.695)

AE-RO4 (0.674)

AE-RO1 (0.508)

Factor 4

Processing activities

AE-RO6 (0.717)

AE-RO11 (0.541)

AE-RO12 (0.535)

$\mathrm{AC}-\mathrm{CE} 3(-0.541)$

Factor 3 (eigenvalue $=1.80,7.49 \%$ of total variance) loaded on three AE-RO items;

Factor 4 (eigenvalue $=1.31,5.44 \%$ of total variance) loaded on three $\mathrm{AE}-\mathrm{RO}$ items and one $\mathrm{AC}-\mathrm{CE}$ item with a negative loading.

\section{Discussion}

\subsection{On the distribution of learning styles}

In Newland et al.'s (1987) study that was conducted with 45 subjects 'displayed an affinity for "active experimentation" and "concrete experience"; Kolb would term these students "accommodators" (p. 4). Newland et al. (1987) called them 'dynamic learners' and explained their tendency as the desire to transform their experience into understanding through external representations as sketches and final drawings. These learners have a preference for both controlling action and sensing needs (Powell and Newland, 1994). The 'dynamic learners' 'can only cope with information in short bursts and therefore enjoy fast-acting learning process like brainstorming' (Newland et al., 1987, p. 11). Also, Newland et al. (1987) explained that simple analogies and use of metaphors would help designers in understanding the basic principles that will guide them in the final drawings. With respect to interpersonal style, 'dynamic learners' are self-centred individuals and not good team members.

In this study, the freshman design students displayed an affinity for 'abstract conceptualisation' and 'reflective observation'; Kolb called them assimilating 
learners. As Hunt (1987) emphasised, these learners do not reflect their feelings in the design process. Newland et al. (1987) called these type of learners as 'contemplative learners' who have preference for abstracting patterns and being patient. 'Contemplative learners' exhibit an information need that is pattern seeking and can enable a thorough understanding of their environment (Powell and Newland, 1994). Also, they explained their strategy as being self-informing one that inhibits the final decisions which are necessary in design practice. The learning style difference between Powell and Newland's (1994) study and this one can be explained in terms of cultural differences or a change in learning styles as a result of time where there is more than a decade between the two studies.

Kolb and Kolb (2005a) classified the architects as assimilating learners in their study and located them at the 'reflective observation' end of the AE-RO axis on the Learning Style Type Grid. Although this study conforms with Kolb and Kolb's (2005a) study, the learning styles of the freshman design students are close to the intersection of the vertical axis $(\mathrm{AC}-\mathrm{CE}=7.44)$ with the horizontal axis $(\mathrm{AE}-\mathrm{RO}=5.20)$ of the Learning Style Type Grid. Therefore, it may be concluded that the freshman design students have a balanced learning style preference by being at a coordinate closer to the intersection of axes compared to the architects in Kolb and Kolb's (2005a) study.

According to Cross (1989), design process is considered as a convergent act that is composed of divergent steps. The convergent act involves the selection of the most appropriate and feasible solution from the alternatives regarding the objectives of the design problem whereas the divergent one deals with producing a wide range of design alternatives (Cross, 1989; Dorst and Cross, 2001; Liu et al., 2003). Since an appropriate strategy in design literature is identified with its potential of design thinking for a satisfactory problem-solution pair (Cross, 1989, 2006), the design strategies should be structured regarding the convergent and divergent acts. The freshman design students with a balanced learning style preference seem to be appropriate for using the multiple divergence-convergence based design strategies. Liu et al. (2003) defined the divergence-convergence based design strategy as 'a series of generation and evaluation rather than a single step of generation and evaluation' (p. 355).

\subsection{On the items}

The primary factor is composed of five negatively loaded CE items and two positively loaded AE items (see Table 2). The primary criterion for the design students was to emphasise that they do not rely on their feelings during the design process. They are near the abstract conceptualisation (AC) end of the perceiving axis (see Figure 1). This shows that during the design process, they do not perceive the environment by relying on their feelings, but they logically analyse ideas and act as a consequence of an intellectual understanding of the 
environment. Also, they declared that they learn best when they experiment by themselves or while observing the results of their work. This means making external representations as sketches and drawings and also, the assessment of their projects by the critiques help them in learning their profession. These findings conform with 'the designerly ways of knowing' as Cross (2001) emphasised the importance of knowing and acting in design process.

The secondary factor is composed two negatively loaded RO items and one CE and one AC positively loaded item (see Table 2). For the students, the secondary criterion is that the designer is not a reserved person during the design process. The design students are near active experimentation (AE) end of the process axis. When they are learning, they have strong feelings and reactions while acting as a rational person.

The tertiary factor is composed of two negatively loaded AE items and one positively loaded AC item (see Table 2). As the first factor they have declared that they like to draw sketches and drawings, but they also admitted that this process is not an active one. This is supported by the third item of this factor that shows this process is dependent upon abstract conceptualisation (AC). It involves logical analysis of ideas, systematic planning and intellectual understanding of the environment.

\subsection{On the bipolar learning dimensions}

Boyatzis and Kolb $(1995,1997)$ developed the Learning Skills Profile (LSP) to assess systematically the adaptive competencies associated with the learning styles. Analysing the relationship between LSP and LSI, Yamazaki et al. (2003) determined the relationships between the two bipolar dimensions and the learning skills. Kolb and Kolb (2005b) found that 'AC-CE was negatively related to the interpersonal skills of leadership, relationship, and help and positively related to the analytical skills of theory building, quantitative analysis, and technology as predicted. The $\mathrm{AE}-\mathrm{RO}$ dimension did not relate to the perceptual/information skills of sense making, information gathering but did relate to the behavioural skills of goal setting and initiative, as predicted' (p. 28). As seen in Table 3, the first factor is a combination of five AC-CE items with positive loadings. The learning style of design students specialising in conceptualisation showed higher levels of skill development in analytical skills (AC) and lower levels of skill development in interpersonal skills (CE). This shows the design students are positively related to the analytical learning skills of theory building, quantitative analysis, and technology and computer. The second, third and fourth factors are combination of three, four and three AE-RO items with positive loadings, respectively. These factors point out that the design students have better behavioural learning skills (AE) compared to perceptual learning skills (RO). Also, it is concluded that these design students have behavioural learning skills of goal setting and they are active and initiative. 


\section{Conclusion}

The ELT (Kolb and Kolb, 2005a) proposed that 'learning is a holistic process of adaptation to the world. Not just the result of cognition, learning involves the integrated functioning of the total person - thinking, feeling, perceiving and behaving' (p. 194). The findings of this study showed that the learning styles of the freshman design students generally are close to the intersection of the axes of the Learning Style Type Grid. Therefore, it may be concluded that the freshman design students have a balanced learning style preference compared to the architects in Kolb and Kolb's (2005a) study. Kolb and Kolb (2005a) have found that learners with balanced learning profiles are more adaptive and flexible learners. The findings in this study also support the previous works of the authors (Demirbas and Demirkan, 2003, 2007) who found in their analysis of the design process that the learning cycle was a recursive one that uses experiencing, reflecting, thinking and acting.

The bipolar perceive dimension $(\mathrm{AC}-\mathrm{CE})$ indicated that the freshman design students are more related to the analytical skills of theory building, quantitative analysis and technology. The bipolar process dimension (AE-RO) showed that the freshman design students have better behavioural skills compared to perceptual learning skills. Also, they do not rely on their feelings during the design process and learn best by external representations. The given critiques also help in developing their projects. During the design process they make the analysis of the environment and use their logic instead of their feelings.

This study is based on one design program at one university and it should be generalised by having data from several institutions. In different studies, it was proposed that the preferred learning styles were generally the reflection of a tendency more than a definite style so an adoption of different learning styles or a possible change in the learning style according to different situations and growing experience might be a possibility (Pinto et al., 1994; Duff, 1997; Busato et al., 1998; Marriott, 2002). Thus, further work may examine the change in the learning styles of design students in the following years and professional life. Moreover, a comparison between different countries may be of interest to scholars who are working in this field.

\section{References}

Akin, O (1986) Psychology of architectural design Pion, London

Askar, P and Akkoyunlu, B (1993) Kolb ogrenme stili envanteri Egitim ve Bilim Vol 87 pp 37-47

Biggs, J (2001) The reflective institution: assuring and enhancing the quality of teaching and learning Higher Education Vol 41 pp 221-238

Boyatzis, R E and Kolb, D A (1995) From learning styles to learning skills: the executive skills profile Journal of Managerial Psychology Vol 10 pp 3-17 
Boyatzis, R E and Kolb, D A (1997) Assessing individuality in learning: the learning skills profile Educational Psychology Vol 11 pp 279-295

Busato, V V, Prins, F J, Elshout, J J and Hamaker, C (1998) Learning styles: a cross-sectional and longitudinal study in higher education The British Journal of Educational Psychology Vol 68 pp 427-439

Cattell, R B (1944) Psychological measurement: normative, ipsative, interactive Psychological Review Vol 51 pp 292-303

Chan, W (2003) Analysing ipsative data in psychological research Behaviormetrika Vol 30 pp 99-121

Coffield, F, Moseley, D, Hall, E and Ecclestone, K (2004) Learning styles and pedagogy in post-16 learning: a systematic and critical review Learning and Skills Research Center, London, UK

Cross, N (1982) Designerly ways of knowing Design Studies Vol 3 No 4 pp 221-227

Cross, N (1989) Engineering design methods John Wiley and Sons, Chichester

Cross, N (2001) Designerly ways of knowing: design discipline versus design science Design Issues Vol 17 pp 49-55

Cross, N (2006) Designerly ways of knowing Springer, London

Demirbas, $\mathbf{O} \mathbf{O}$ (2001) The relation of learning styles and performance scores of the students in interior architecture education, unpublished $\mathrm{PhD}$ dissertation, Bilkent University, Ankara

Demirbas, O O and Demirkan, H (2003) Focus on architectural design process through learning styles Design Studies Vol 24 pp 437-456

Demirbas, $O$ O and Demirkan, H (2007) Learning styles of design students and the relationship of academic performance and gender in design education Learning and Instruction Vol 17 pp 345-359

Dewey, J (1933) How we think: a restatement of the relation of reflective thinking to the educative process D.C. Heath, Boston (Revised ed.)

Dewey, J (1938) Experience and schooling McMillan Publishing Company, New York

Dorst, K and Cross, N (2001) Creativity in design process: co-evolution of problem-solution Design Studies Vol 22 pp 425-437

Duff, A (1997) Validating the learning styles questionnaire and inventory of learning process in accounting: a research note Accounting Education Vol 6 pp 263-272

Guild, P (1994) Making sense of learning styles School Administrator Vol 51 pp 8-13

Hartman, V F (1995) Teaching and learning style preferences: transitions through technology VCCA Journal Vol 9 pp 8-20

Hermanussen, J, Wierstra, R F A, De Jong, J A and Thijssen, J G L (2000) Learning styles in vocational work experience Journal of Vocational Education Research Vol 25 pp 445-471

Hunt, D E (1987) Beginning with ourselves in practice theory and human affairs Brookline Books, Cambridge, MA

Kaiser, H F (1960) The application of electronic computers to factor analysis Educational and Psychological Measurement Vol 20 pp 141-151

Kayes, D C (2002) Experiential learning and its critics: preserving the role of experience in management education Academy of Management Learning and Education Vol 1 pp 137-149

Kolb, D A (1984) Experiential learning: experience as the source of learning and development NJ Prentice Hall, Englewood Cliffs

Kolb, D A (1999) Learning style inventory Hay/McBer, Boston

Kolb, A Y and Kolb, D A (2005a) Learning styles and learning spaces: enhancing experiential learning in higher education Academy of Management Learning and Education Vol 4 pp 193-212 
Kolb, A Y and Kolb, D A (2005b) The Kolb learning style inventory - version 3.1: technical specifications Hay Resources Direct, Boston, MA

Kvan, T and Yunyan, J (2005) Students' learning styles and their correlation with performance in architectural design studio Design Studies Vol 26 pp 19-34

Lawson, B (1990) How designers think: the design process demystified Butterworth Architecture, London

Liu, Y C, Bligh, T and Chakrabarti, A (2003) Towards an 'ideal' approach for concept generation Design Studies Vol 24 pp 341-355

Marriott, P (2002) A longitudinal study of undergraduate accounting students' learning style preferences at two UK universities Accounting Education Vol 11 pp 43-62

Newland, P, Powell, J A and Creed, C (1987) Understanding architectural designers' selective information handling Design Studies Vol 8 pp 1-17

Pedhazur, E J and Schmelkin, L P (1991) Measurement, design and analysis: an integrated approach Lawrence Erlbaum, Hillsdale, NJ

Pinto, J K, Marshall, M A and Bayle, E J (1994) A three-year longitudinal study of changes in student learning styles Journal of College Student Development Vol 35 pp 113-119

Powell, J A and Newland, P (1994) Informing multimedia: a sensitive interface to data for construction design professionals Design Studies Vol 15 pp 285-316

Reitman, R R (1965) Cognition and thought: an information processing approach John Wiley and Sons, NY

Rittel, H (1972) On the planning crisis: systems analysis of the 'first and second generations' Bedriftsøkonomen Vol 8 pp 390-396

Schon, D A (1983) The reflective practitioner how professionals think in action Basic Books/Harper Collins

Schon, D A (1984) The architectural studio as an exemplar of education for reflection-in action Journal of Architectural Education Vol 38 pp 2-9

Schon, D A (1987) Educating the reflective practitioner: towards a new design for teaching in the professions Jossey-Bass Publishers, San Francisco, CA

Simon, H A (1996) The sciences of the artificial ( ${ }^{\text {rd }}$ edn) MIT Press, Cambridge, MA [ $1^{\text {st }}$ ed published in 1969]

Smith, D M and Kolb, D A (1996) User's guide for the learning-style McBer and Company, Boston

Vermetten, Y J, Lodewijks, H G and Vermunt, J D (1999) Consistency and variability of learning strategies in different university courses Higher Education Vol 37 pp 1-21

Waks, L J (1999) Reflective practice in the design studio and teacher education Journal of Curriculum Studies Vol 31 pp 303-316

Waks, L J (2001) Donald Schon's philosophy of design and design education International Journal of Technology and Design Education Vol 11 pp 37-51

Willcoxson, L and Prosser, M (1996) Kolb's learning style inventory (1985): review and further study of validity and reliability British Journal of Educational Psychology Vol 66 pp 251-261

Yamazaki, Y Murphy, V and Puerta, M (2003) Learning styles and learning skills in higher education: an empirical study of their relationship using Kolb's experiential learning theory, Working paper, Department of Organizational Behavior Case Western Reserve University 